\title{
The rare earth element geochemistry of hydrothermal sediments from the East Pacific Rise: Examination of a seawater scavenging mechanism
}

\author{
DOUGLAS E. RUHLIN and ROBERT M. OWEN ${ }^{1}$ \\ Department of Atmospheric and Oceanic Science, The University of Michigan, Ann Arbor, MI 48109, U.S.A.
}

(Received January 29, 1985; accepted in revised form November 25, 1985)

\begin{abstract}
The sediments recovered during DSDP Leg 92 (Site 598) include a complete $16 \mathrm{~m} . y$. record of hydrothermal sedimentation along the western flank of the East Pacific Rise at $19^{\circ} \mathrm{S}$. Fifty samples from this sediment column were analyzed to test the hypothesis that the REE composition of the hydrothermal component is primarily acquired via scavenging from seawater. Site 598 provides an ideal sample suite for this purpose: the sediments are lithologically "simple," primarily consisting of a mixture of hydrothermal materials and biogenous carbonates; the composition of the hydrothermal component is essentially constant through space and time; and the sediments have undergone minimal diagenetic alteration.

The following observations suggest the above-stated hypothesis is true. The $\mathrm{Ce}$ anomaly as well as key indices of light and heavy REE behavior all show that the REE pattern of hydrothermal sediments approaches that of seawater with increasing paleodistance from the rise crest. Moreover, shale-normalized REE patterns are similar to that of seawater, varying only in absolute REE content: the REE content increases with distance from the paleo-rise crest and exhibits a pronounced increase in sediments deposited below the paleolysocline. Based on significant correlative relationships between paleodistance from the rise crest and both the concentration and mass accumulation rates (MARs) of REEs and Fe, we conclude the REEs in the hydrothermal component are derived from the interaction of seawater and $\mathrm{Fe}$ in the hydrothermal plume.
\end{abstract}

\section{INTRODUCTION}

INVESTIGATIONS OF hydrothermal precipitates from various locations (e.g., EDMOND et al., 1979a,b), laboratory experimental studies (e.g., MOTTL and SEYFRIED, 1980), and the results of quantitative simulation models (e.g., BOWERS and TAYLOR, 1983) all have established that these deposits can and often do exhibit a broad range of chemical compositions. For any given element, this compositional variability may arise from differences in the primary composition of the hydrothermal fluid, variations in key parameters (temperature, permeability, water-rock ratio) during seawaterbasalt interaction, the degree of subsurface mixing between seawater and the hydrothermal fluid, and chemical reactions between precipitates in the debouched fluid and ambient bottom waters. Within this context, the general objective of this study was to determine the factors which influence the rare earth element (REE) content of hydrothermal deposits. Specifically, we have investigated the REE geochemistry of hydrothermal sediments recovered from Site 598 $\left(19^{\circ} 00.283 ' \mathrm{~S}, 124^{\circ} 40.606^{\prime} \mathrm{W}\right)$ during Leg 92 of the Deep Sea Drilling Project (DSDP), which represent a complete record of hydrothermal sedimentation at the East Pacific Rise (EPR) over the past 16 million years.

Hydrothermal sediments from the Bauer Deep, the East Pacific Rise, and basal metalliferous sediments from DSDP sites all have REE patterns which strongly resemble seawater patterns (BENDER et al., 1971; DYMOND et al., 1973). Although REE depletion and a REE abundance pattern similar to that of seawater are considered characteristic of newly formed hydrother-

\footnotetext{
${ }^{1}$ Author to whom all correspondence should be addressed.
}

mal precipitates (ToTH, 1980), there is evidence that REE levels of materials that have been carried far away from active vents will be higher and will be particularly enriched in Ce, possibly due to REE scavenging by the particulates. DYMOND et al. (1973) observed that the $\mathrm{Ce} / \mathrm{Sm}$ ratio in hydrothermal sediments is negatively correlated with iron and seems to increase in metalliferous sediments away from the rise crest; however, they also note that the total REE enrichment observed in their samples could have been due to small amounts of phosphatic fish debris present in all samples. LYLE (1981) found that rise crest ferromanganese coatings have lower absolute REE abundances and a REE pattern more similar to that of seawater than coatings from off the rise crest. Samples from off the rise crest in LYLE's (1981) study also were much more highly enriched in $\mathrm{Ce}$, as are ferromanganese nodules. However, considerable caution must be exercised in making any analogy between ferromanganese coatings, presumably derived from a hydrogenous source, and the metalliferous sediments resulting from hydrothermal sources. Although these deposits may have similar mineralogies, their compositional differences are quite pronounced (CRONAN, 1980).

In summary, the limited sediment composition data presently available do not permit a definitive interpretation of these results, but do strongly suggest a testable hypothesis: the primary mechanism responsible for the acquisition of REEs by hydrothermal precipitates involves the scavenging of these elements from seawater. Investigations of REE profiles in seawater also support this hypothesis. For example, KLINKHAMMER et al. (1983) recently have observed significant differences in the concentration $v s$. depth profiles of REEs in seawater near hydrothermal vents compared to profiles obtained from stations not influenced by hydrothermal 
plumes. These authors suggest a number of possible processes which could account for these differences, but emphasize that the most plausible mechanism is one which involves scavenging of REEs by hydrothermal precipitates. Such a process would be consistent with previous observations that manganese and, particularly, iron oxyhydroxides exhibit a high affinity for scavenging REEs in both marine and lacustrine waters (e.g., GOLDBERG, 1963; PIPER, 1974a,b; OWEN and MACKIN, 1980, and many others).

As is elaborated upon below, the sediments collected during DSDP Leg 92 are lithologically "simple" (i.e., they primarily consist only of biogenous carbonates and hydrothermal precipitates) and apparently have experienced little or no diagenetic alteration. Consequently, these sediments are particularly well suited for carrying out a further examination of the above stated hypothesis. In the present study we have attempted to verify or reject this hypothesis on the basis of observed relationships between: (1) the concentration and mass accumulation rates (MARs) of Fe and the REEs in the hydrothermal sediments; and (2) systematic variations in the REE abundances and patterns of hydrothermal sediments vs. certain proxy indicators of the exposure of these precipitates to seawater.

\section{ANALYTICAL PROCEDURES}

A total of $\mathbf{5 0}$ samples from DSDP Hole $\mathbf{5 9 8}$ were analyzed for $\mathrm{Mn}, \mathrm{Fe}, \mathrm{Ni}, \mathrm{Zn}, \mathrm{Ba}, \mathrm{Cl}, \mathrm{La}, \mathrm{Ce}, \mathrm{Nd}, \mathrm{Sm}, \mathrm{Eu}, \mathrm{Tb}, \mathrm{Yb}$, and Lu by instrumental neutron activation analysis (INAA) at the Phoenix Memorial Laboratory, The University of Michigan, using stendard INA procedures (GORDON et al., 1968; DAMS and Rosans, 1970). A preliminary test showed that the presence of a small amount of sea salt (as freeze drying residue) would not interfere with our results; consequently, sample preparation did not require successive washing and drying cycies. This teat also showed that thermal fission of $U$ (e.g. DE BAAR, 1983) present in our samples (either from seawater or by hydrothermal processes) did not have a significant effect on the precision of our REE data. The calcium carbonate content of all samples was determined using a pressure-bomb technique, and the sea salt content of the freeze-dried residue was estimated by assuming that all $C$ in the residue was derived from sea salt ( $\mathrm{Cl}=55.04 \%$ by weight of sea salt).

A detailed description of sample preparation procedures for INAA and reactor/counting conditions for these analyses is given elsewhere (RUHU WN and OWEN, in press). Replicate analyses of USGS G-2 standard and "Standard Pacific Sediment" (OWEN and RUHuN, in press) were conducted to evaluate analytical precision; a comparison of our results ws. suggested values for these standards is given in Table 1.

\section{RESULTS AND DISCUSSION}

A summary of the elemental concentrations determined for each sample is presented in Table $2\left(\mathrm{CaCO}_{3}\right.$, $\mathrm{Cl}$ and $\mathrm{Ba}$ are reported as amount determined in bulk sample; all other values are reported on a carbonatefree, salt-free basis). Also included in Table 2 are sample ages, calculated from shipboard biostratigraphy and core depth measurements, and the distance between the point at which the sediments in the samples were deposited and the position of the paleorise crest. These distances were determined based on the present dis- wars 1. Sumary of Raplicate Annlyoes of tses-62 Stanchurd tor Fe and nEs'a.

\begin{tabular}{|c|c|c|c|c|}
\hline $\operatorname{Rl}=n t^{1}$ & $\operatorname{masin}^{2}$ & $\begin{array}{l}\text { Sta. } \\
\text { Dev. }\end{array}$ & $\begin{array}{c}\text { Relative sta. Dev. } \\
\text { (e) }\end{array}$ & $\begin{array}{l}\text { Suggeated } \\
\text { wilue }\end{array}$ \\
\hline 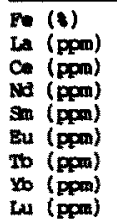 & $\begin{array}{c}1.88 \\
86.2 \\
160 \\
65.7 \\
7.58 \\
1.47 \\
0.42 \\
0.81 \\
0.09\end{array}$ & $\begin{array}{c}0.06 \\
5.87 \\
14.4 \\
11.7 \\
0.16 \\
0.09 \\
0.12 \\
0.14 \\
0.01\end{array}$ & $\begin{array}{c}3.19 \\
6.81 \\
9.00 \\
17.8 \\
2.11 \\
6.12 \\
28.6 \\
17.3 \\
11.1\end{array}$ & $\begin{array}{c}1.88 \\
96 \\
150 \\
60 \\
7.3 \\
1.5 \\
0.54 \\
0.89 \\
0.11\end{array}$ \\
\hline
\end{tabular}

1. All analyoos by mik.

2. Baced upon 8 replicate analyas.

3. Suggested values for uses-62 standurd from Flanigan (1973).

tance of Site 598 from the rise crest $(1150 \mathrm{~km})$, the basement age of Site 598 (16 m.y.), and applicable spreading rates (REA, in press). Various geochemical anomalies indicative of hydrothermal plumes suggest that the plumes in this region of the South Pacific (DYMOND, 1981; LuPTON and CRAIG, 1981) are commonly transported well beyond the present distance between Site 598 and the rise crest $(1150 \mathrm{~km})$; hence we infer that Site 598 sediments reflect a continuous record of the deposition of hydrothermal precipitates.

The chemical composition of sediments is sensitive to variations in the flux of sedimentary materials from various sources which ultimately form the sediments in question. Consequently, to evaluate variations in the mass flux of individual elements, elemental mass accumulation rates (MARs) were calculated and are reported in Table 3. Elemental MARs are the product of the linear sedimentation rate, the sediment dry bulk density, and the bulk concentration of the individual element as determined in this study. Values for DSDP Site 598 linear sedimentation rates and dry bulk densities are from LEINEN $e t$ al. (in press).

\section{Compositional integrity of the hydrothermal component}

An accurate assessment of the influence of seawater scavenging on the REE geochemistry of the sediments at Site 598 is directly related to the number and complexity of other possible causes of REE compositional variation. If the sediments are derived from multiple sources, for example, or if they have undergone extensive compositional changes as a result of diagenesis, our ability to interpret the REE data would be correspondingly diminished. Several considerations suggest these types of problems are minimal in the present study.

Based on compositional similarities that exist among hydrothermal sediments through space and time in this portion of the Pacific Ocean, DYMOND (1981) concluded that there has been remarkably little variation in the initial composition of the hydrothermal fluid over the past 30-60 m.y. Moreover, a major consideration in the positioning of Site 598 (as well as other Sites in the Leg 92 cruise track) was prior knowledge 


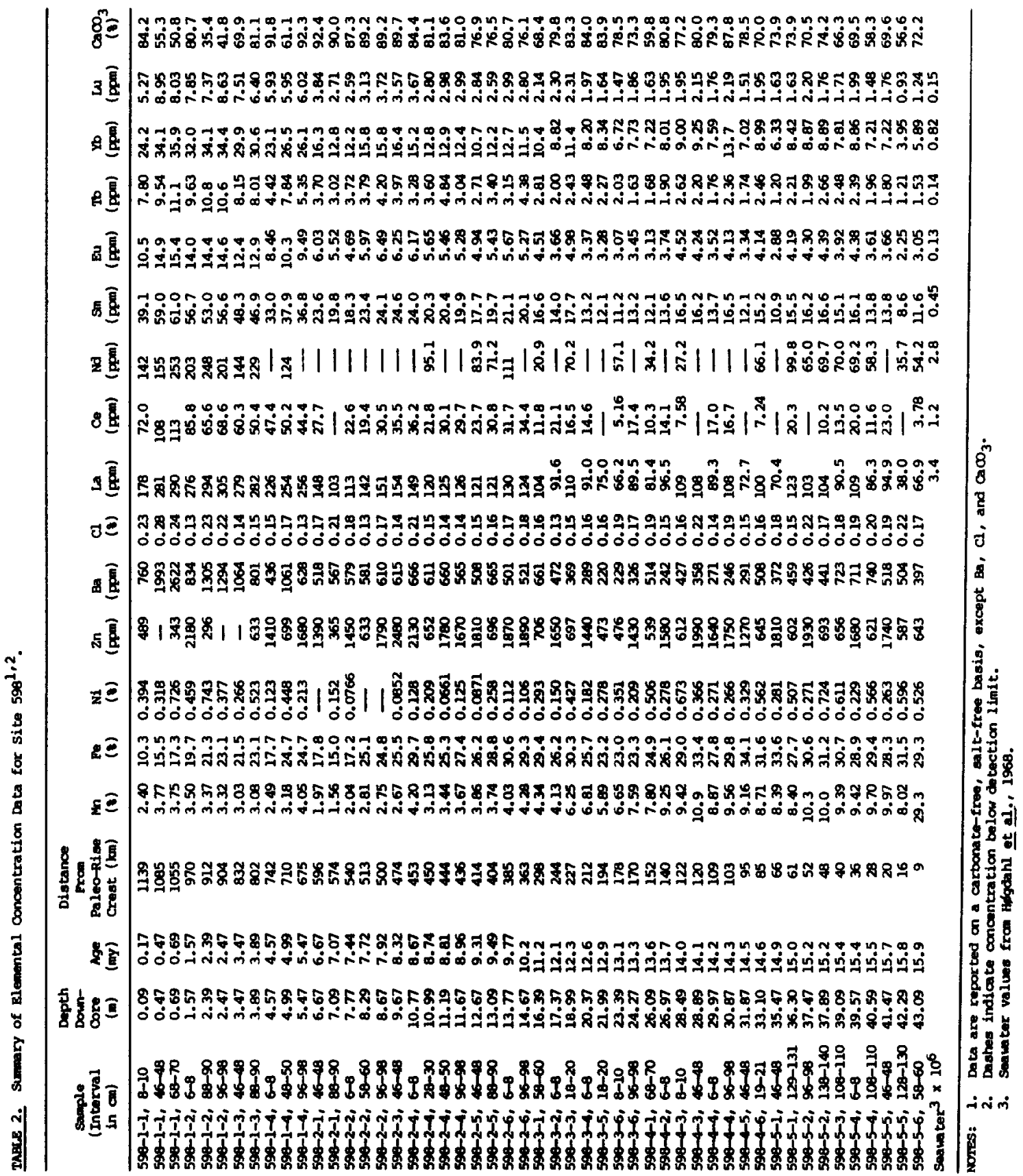


TABLE 3. Sumery of Aasamulation Rate Deta for Site 598.

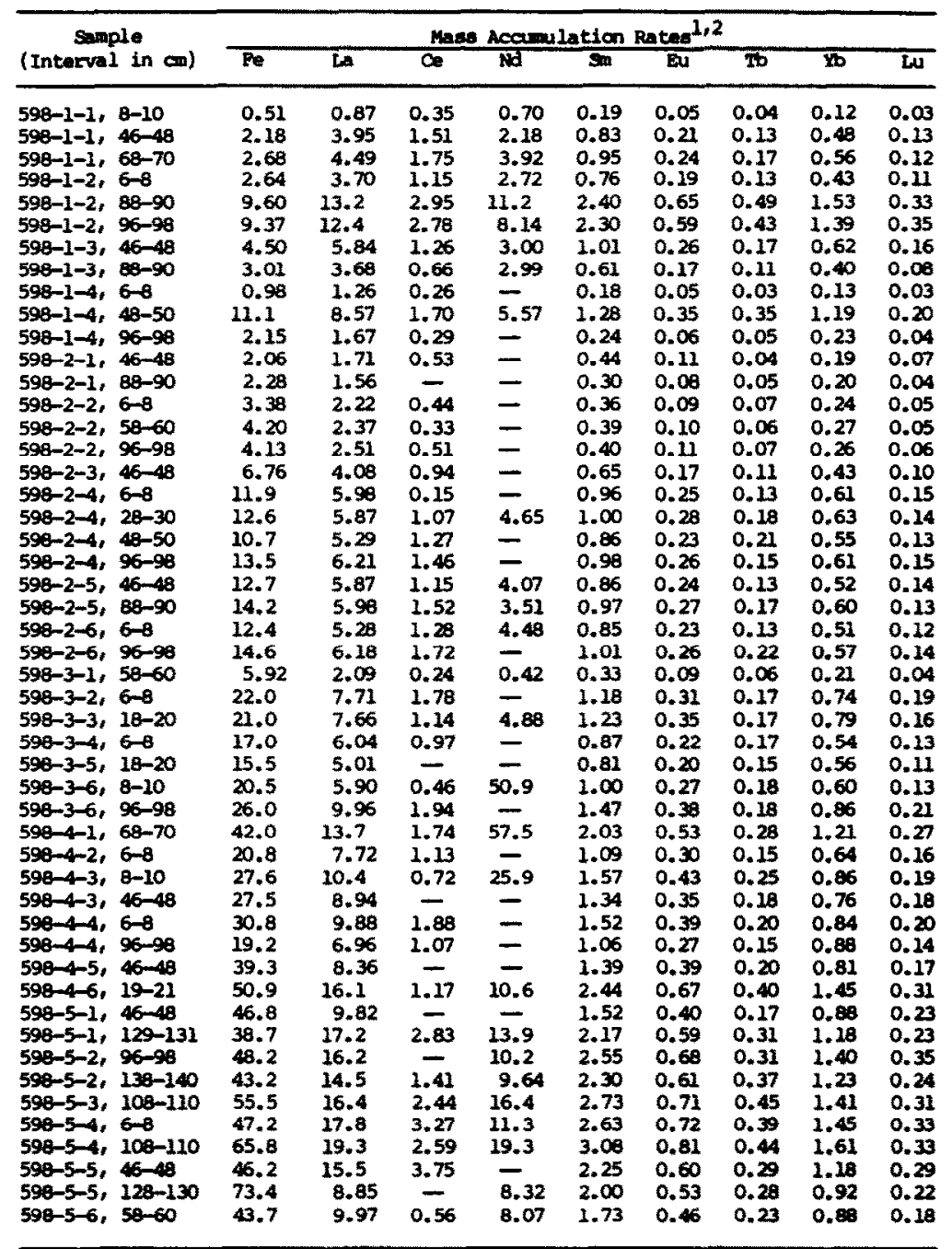

NOTEs: 1. Masa accumula bion rafes for Pe are expreased as ag $\mathrm{cm}^{-2} \cdot \mathrm{ky}^{-1}$; for

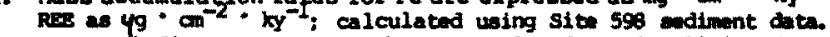

2. Dahes indicate concentration was below detection ilmit; therefore, MAR could not: ba calculated.

(LEINEN, 1981) that the sediments here were likely to be lithologically simple and unaffected by significant diagenetic alteration. This was done to ensure minimal dilution of the hydrothermal component by terrigenous and biogenic materials, and to avoid the possibility of remobilization of trace elements by reducing conditions associated with organic carbon diagenesis. On the basis of shipboard and subsequent laboratory examination of Site $\mathbf{5 9 8}$ sediments, it appears that this sampling strategy was successful: the sediments recovered here reflect a highly oxidized system consisting of only two major components, biogenic carbonates and hydrothermal precipitates, with only trace amounts of material from other sources and no evidence of organic diagenesis. Furthermore, shipboard porewater analyses (by J. Geiskes and J. Boulegue) indicated there was no reductive remobilization of manganese, the most redox-sensitive of the common transition elements. The lack of a significant phosphatic fish debris component (as determined by microscopic examination) in these sediments is particularly crucial, since it has been suggested that this phase may be an important controlling factor of the REE geochemistry of slowly accumulating marine sediments (DYMOND, 1973; DYMOND and EKLUND, 1978).

The most compelling argument that the composition of the hydrothermal component of Site 598 sediments has remained constant is obtained from a quantitative comparison of the down-core geochemistry of the hydrothermal component $v s$. that of their modern analogs. DYMOND (1981) found that the composition of the hydrothermal component of surficial sediments in the general region of the South Pacific which includes Site $\mathbf{5 9 8}$ is remarkably constant; so constant, in fact, that it can be readily identified and distinguished from sedimentary material from other sources on the basis 
of highly characteristic ratios among various elements which are representative of a pure end-member hydrothermal component. If the composition of the hydrothermal component in Site 598 sediments has remained constant over space and time, then the elemental ratios determined for our down-core samples should be reasonably close to those reported for surficial sediments. On the other hand, if the original composition of the hydrothermal source has changed and/or if there has been diagenetic remobilization and segregation of trace elements, then these effects should be manifested by significant differences in a comparison of elemental ratios.

DYMOND (1981) determined the concentration of Fe in pure hydrothermal material to be $34.8 \%$ and calculated all elemental ratios relative to this element. Consequently, we calculated a linear regression for certain elements $v s$. Fe in our 50 down-core samples, and then substituted this $\mathrm{Fe}$ value into each equation to obtain predicted end-member hydrothermal concentrations for each element. Ratios between each of these end-member concentrations and Fe were then calculated. A comparison of our values vs. those reported by DYMOND (1981) is shown in Table 4. In general, there is excellent agreement between these values. The close agreement between the $\mathrm{Mn} / \mathrm{Fe}$ ratios is particularly encouraging, since the diagenetic behavior of these two elements is well understood (KRAUSKOPF, 1957; LYNN and BONATTI, 1965) and we regard this ratio as the most sensitive indicator of diagenetic remobilization. DYMOND (1981) found a relatively high error associated with the $\mathrm{Ni} / \mathrm{Fe}$ ratio determined in his study and suggested that this might be due to a breakdown in the constant composition assumption for these elements. This factor could account for the rather poor agreement between the $\mathrm{Ni}$ / Fe ratios shown in Table 4.

On the basis of the considerations discussed above, we conclude: (1) the original composition of the hydrothermal component in Site 598 sediments has not varied with time or as a result of diagenetic alteration; (2) the influence of trace amounts of terrigenous, hydrogenous or non-carbonate biogenic material (e.g., siliceous material, phosphatic fish debris) in our samples is minimal; and, therefore, (3) it is reasonable to interpret variations in the REE geochemistry of this component as being primarily caused by the interaction of hydrothermal precipitates and seawater.

TABCE 4. Comparison of Elemental Ratios for Pure Hydrothermal Material in Site 598 Sediments vo. South Pacific surficial sediments.

\begin{tabular}{|c|c|c|}
\hline Ratio & site 598 & $\begin{array}{l}\text { South Pecific } \\
\text { Surficial sediented }\end{array}$ \\
\hline $\begin{array}{l}\mathrm{m} / \mathrm{Fe} \\
\mathrm{2n} / \mathrm{Pe} \\
\mathrm{Ba} / \mathrm{Be} \\
\mathrm{N} / \mathrm{Pe}\end{array}$ & $\begin{array}{l}0.280 \\
0.0017 \\
0.0049 \\
0.0221\end{array}$ & $\begin{array}{l}0.2000 \\
0.0019 \\
0.0050 \\
0.0009\end{array}$ \\
\hline
\end{tabular}

1. Fram Dyiond (1981).

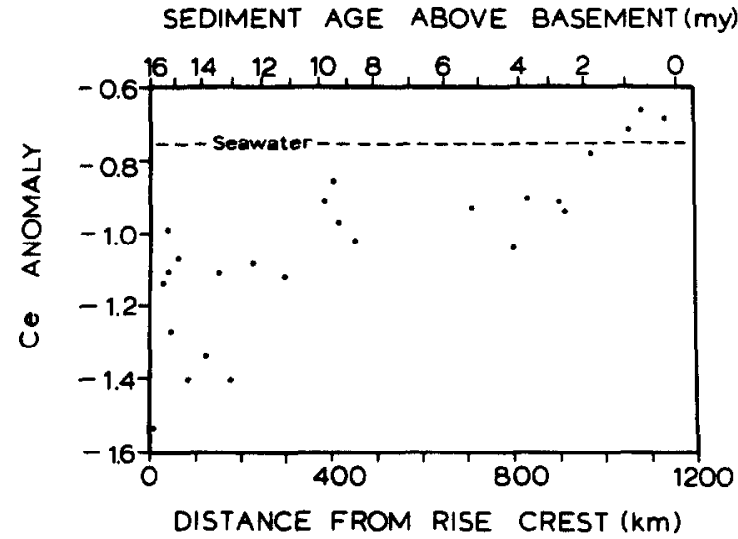

FIG. 1. Plot of the Ce anomaly vs. paleodistance, Site 598 samples. Dashed line indicates average seawater $\mathrm{Ce}$ anomaly value using data of HeGDAHL et al., 1968. Ce anomaly for Southeast Pacific deep waters $(2500 \mathrm{~m})=-1.2$.

\section{REE geochemistry}

The most prominent features of the REE pattern of seawater include (e.g., ELDERFIELD and GREAVES, 1982): (1) a strong negative Ce anomaly, which occurs because this element can be oxidized to the +4 oxidation state, which has a relatively high affinity for solid phases; and (2) a pronounced enrichment of the heavy REEs (HREE) relative to the light REEs (LREE), which is due to the relatively greater stability of HREE complexes in seawater. Certain ratios among the REE which are considered characteristic of these features serve as a measure of how closely the REE pattern of any given marine phase approaches that of seawater. For example, Fig. 1 clearly shows the magnitude of the Ce anomaly of Site 598 sediments approaches that of average seawater with increasing distance from the rise crest. (Ce anomaly $=\log (\mathrm{Ce} /(2 / 3 \mathrm{La}+1 / 3 \mathrm{Nd})$ ), where the element symbols refer to shale-normalized contents, and is an index of the relative availability of Ce; ELDERFIELD and GREAVES, 1981.) Similarly, significant ( 0.05 level) correlations between both the $\mathrm{La} /$ $\mathrm{Sm}$ ratio (a measure of LREE behavior) and the $\mathrm{Yb} /$ Sm ratio (a measure of HREE behavior) vs. paleodistance both indicate that the REE patterns of Site 598 sediments become more like that of seawater with increasing distance from the rise crest. Inter-element correlations among the REEs are all strongly positive, indicative of the coherency of chemical behavior of these elements in the marine environment (PIPER, 1974a,b; ELDERFIELD and GREAVES, 1982).

Recent work (KIINKHAMMER et al., 1983; DE BAAR, 1985) has shown there are pronounced differences in the REE concentrations of Pacific and Atlantic seawater, and thus a comparison of our data with average seawater (as in Fig. 1) may be somewhat misleading without further elaboration. For example, the $\mathrm{Ce}$ anomaly calculated as above using the data reported by KIINKHAMMER et al. (1983) for deep waters ( 2500 $\mathrm{m}$ ) of the Southeast Pacific is about -1.2, as compared to the average seawater value of -0.74 . Consequently, 
the Ce anomaly values of the distal hydrothermal precipitates reported here are actually significantly less negative than those of the surrounding seawater. The pronounced negative $\mathrm{Ce}$ anomaly of seawater has been attributed to oxidative scavenging of $\mathrm{Ce}$ (IV) onto particulate phases, especially ferromanganese nodules (PIPER, 1974a). Our data suggest hydrothermal precipitates may also be important in this regard.

Statistically significant $(0.05$ level $)$ co-variant trends between several of the variables reported in Tables 2 and 3 support the argument that REEs are scavenged from seawater by hydrothermal precipitates. As shown in Fig. 2, the MARs of Fe and the REEs generally decrease with increasing paleodistance from the rise crest, while the concentration of REEs in Site 598 sediments increases with increasing distance from the rise creast. "Spikes" in each of these plots (e.g., at 3-5 m.y.)
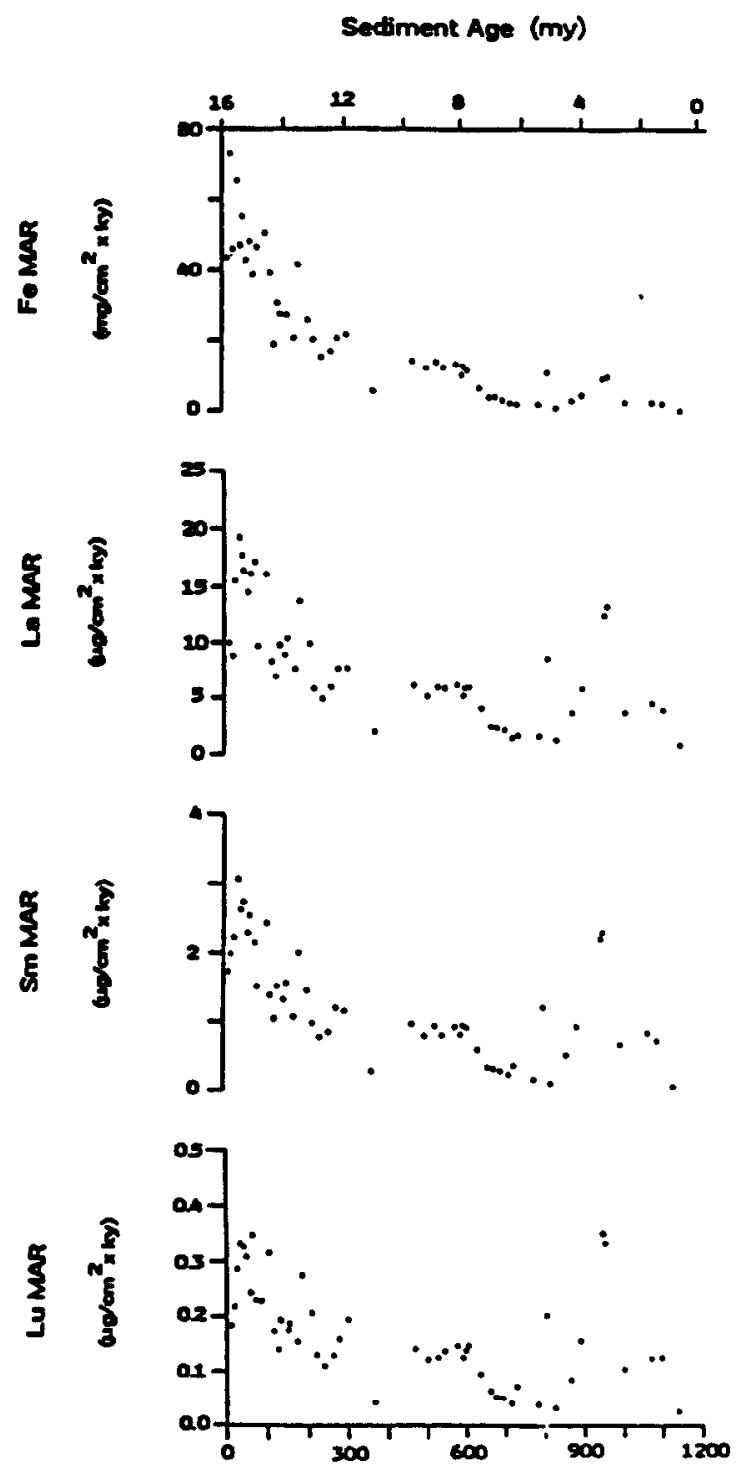

Oistance trom Paleo-Rise Crest (km)

Fig. 2. Mass accumulation rates for Fe and some representative REEs $\boldsymbol{v}$. paleodistance.

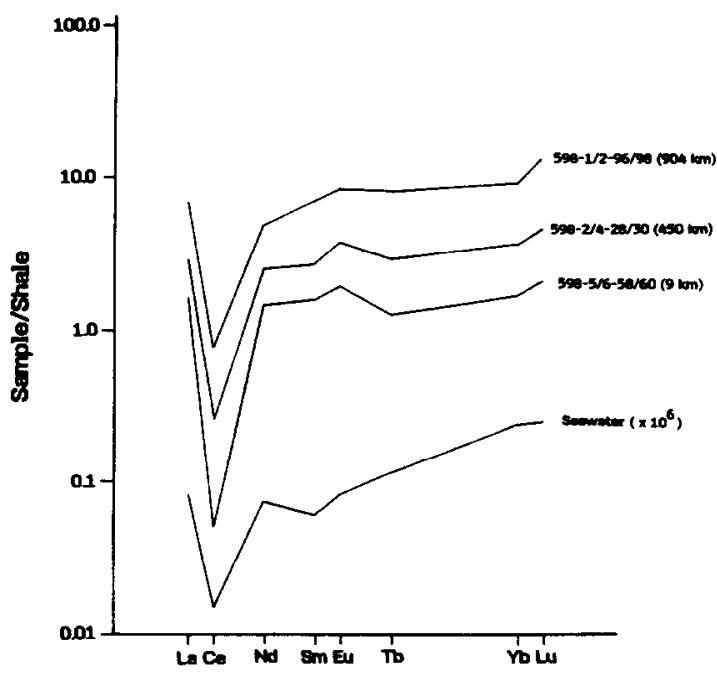

FIG. 3. Shale-normalized REE patterns for representative Site 598 samples and seawater ( $\times 10^{6} ;$ HøGDAHL et al., 1968). Values in parentheses indicate sample distance from the paleorise crest. Shale data from HASKIN et al., 1966.

are believed to be the result of periods of markedly increased hydrothermal activity relative to present leveis (LYLE et al., in press). Individual REE concentrations (except $\mathrm{Ce}$ ) are positively correlated with $\mathrm{Fe}$ concentration, but negatively correlated with the Fe MAR. Shale-normalized REE abundance patterns for a few representative samples from Site 598 are shown in Fig. 3; the abundance patterns for all samples in this study fall within the range defined by the two extremes shown in this plot. The REE patterns of all samples are very similar to that of seawater (Fig. 3) and differ only in absolute REE abundance; here again it is observed that sediments deposited near the rise crest have the lowest REE abundances, and that absolute REE abundances increase with increasing paleodistance from the rise crest. The REE patterns of all Site 598 sediments are very similar, and (with the possible exception of the Ce anomaly) show no obvious evidence of a transition in pattern with distance towards an authigenic REE pattern; a pattern characteristic of slowly accumulating sediments such as those deposited below the lysocline or CCD, or those with little or no hydrothermal component. Authigenic REE fluxes, which may be comparable in magnitude to the distal hydrothermal fluxes presented here, result in a very different sedimentary REE pattern-one which is nearly the mirror image of Site 598 sediments (e.g., a pronounced positive Ce anomaly, light REE enrichment; THOMSON et al., 1984).

The most conclusive evidence in support of a seawater scavenging mechanism is summarized in Fig. 4. Here we observe that the absolute abundance of REEs per unit of $\mathrm{Fe}$ increases significantly with increasing paleodistance from the rise crest and exposure to seawater. We have normalized REE to Fe for two reasons: 1) Site 598 sediments are predominantly composed of only two phases (hydrothermal precipitates and bio- 


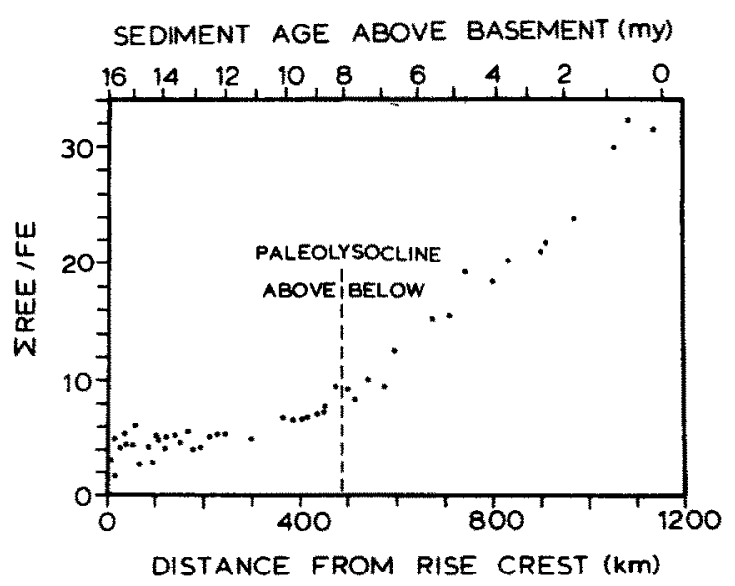

FIG. 4. Plot of REE abundance (expressed as REE sum, excluding Nd due to limited data) per unit of Fe in bulk sample vs. paleodistance. Dashed line indicates approximate position at which sediments were deposited above and below the paleolysocline.

genic carbonates) of which Fe will be almost exclusively associated with, and indicative of, the hydrothermal component; and 2) Fe oxyhydroxides, a major component of hydrothermal precipitates, should be the most effective scavenger of REE in hydrothermal sediments, if indeed scavenging is occurring. The observed increase in the REE/Fe ratio is gradual in sediments deposited above the paleolysocline, and quite pronounced for sediments deposited below the paleolysocline. (The position of the paleolysocline shown in Fig. 4 is taken from LEINEN et al., in press.) Apparently, scavenging of REEs by hydrothermal precipitates occurs both during transport and after deposition. The onset of rapid carbonate dissolution in sediments deposited below the lysocline minimizes burial rates and prolongs the duration of exposure of the hydrothermal residue in these sediments to seawater. This would permit the scavenging process to continue for relatively longer time periods compared to that experienced by hydrothermal materials deposited above the lysocline. In this respect the scavenging of REEs by hydrothermal sediments may be similar to the acquisition of various trace elements by authigenic materials such as ferromanganese nodules. It has been observed that the uptake of elements such as $\mathrm{Ni}, \mathrm{Cu}$ and $\mathrm{Zn}$ is enhanced in ferromanganese nodules and encrustations which form in areas having relatively low sedimentation rates or in nodule fields which extend below the lysocline or the CCD; however, the detailed chemical mechanism of this process is not yet clear, since other factors such as the oxygen content of the bottom waters and the mineral phases within the nodules (and presumably the hydrothermal materials) may also play a key role in the scavenging process (CRONAN, 1980).

\section{SUMMARY AND CONCLUUSIONS}

The sediments present at DSDP Site 598 represent a complete record of hydrothermal activity at the EPR for the past 16 m.y. Several aspects of these deposits permit a detailed examination of the REE geochemistry of the hydrothermal component. Site 598 sediments contain only two major lithologic components: biogenic carbonates and hydrothermal precipitates. Key inter-element ratios calculated for $\mathbf{5 0}$ down-core samples at Site 598 are in excellent agreement with similar ratios calculated by DYMOND (1981) for pure hydrothermal surficial sediments. This agreement indicates the bulk composition of the original hydrothermal component has remained constant through space and time, and has not been changed by contamination from trace components or by diagenetic alteration.

The various trends and inter-element relationships discussed in this report are consistent with the following conceptual model for the acquisition of REEs by hydrothermal precipitates. Iron oxyhydroxides in the hydrothermal plume begin scavenging REEs from seawater as soon as the hydrothermal plume is ejected into bottom waters. Rapid burial (high MARs) of these precipitates near the rise crest minimizes their exposure to seawater and results in basal sediments which exhibit a seawater-like REE pattern and relatively low REE abundances. The scavenging process continues as some of the precipitates disperse away from the injection point, resulting in relatively higher REE concentrations in precipitates which have been transported significant distances from the rise crest. The sharp increase observed in the REE/Fe ratio which corresponds to the position of the paleolysocline indicates that REE scavenging continues as a post-depositional process, and is especially evident in hydrothermal materials which have been maintained at or near the sediment-water interface for prolonged periods due to reworking by bottom currents, carbonate dissolution, or lower bulk sedimentation rates. Observed trends in various geochemical indices of REE behavior show that the REE patterns of distal hydrothermal materials are even more seawater-like than their proximal counterparts.

Acknowledgements-We thank our colleagues on board Glomar Challenger during DSDP Leg 92 for their assistance in obtaining the samples and generating the shipboard data used in this study, and for making a long cruise a very pleasant one. M. Lyle, M. Kastner, D. K. Rea, and M. Leinen provided helpful comments and discussion concerning various aspects of this study. We are grateful to H. Elderfield, G. Klinkhammer, and W. Seyfried for comments and suggestions they offered based on a review of an earlier version of this paper. This research was supported in part by a Rackham Faculty Research Award and by the National Science Foundation under Grant No. OCE-8410034.

\section{Editorial handling: $\mathbf{H}$. Elderfield}

\section{REFERENCES}

Bender M., Broecker W., Gornttz V., MmDel U., KAY R., SUN S. S. and BISCA YE P. (1971) Geochemistry of three cores from the East Pacific Rise. Earth Planet. Sci. Lett. $12,425-433$.

BOWERS T.S. and TAYLOR H. P. (1933) Chemical and isotopic mass transfer calculations pertaining to seafloor hydro- 
thermal systems.Geol. Soc. Amer. Abstract with Programs $15,531$.

Cronan D. S. (1980) Underwater Minerals. Academic Press, 362 pp.

DAMS R. and RoBBINS V. A. (1970) Nondestructive activation analysis of environmental samples. The Univ. of Michigan, Great Lakes Research Div., Tech. Report No. 48, Ann Arbor, Michigan.

DE BAAR H. J. W. (1983) The marine geochemistry of the rare earth elements. Ph.D. thesis, MIT, 273 pp.

DE BAAR H. J. W., BACON M. P., BREWER P. G. and BRULAND K. W. (1985) Rare earth elements in the Pacific and Atlantic oceans. Geochim. Cosmochim. Acta 49, 1943-1960.

DYMOND J. (1981) The geochemistry of Nazca Plate sediments: An evaluation of hydrothermal, biogenic, detrital and hydrogenous sources. Geol. Soc. Amer. Mem. 154, 133 173.

DYMOND J. and EKLUND W. (1978) A microprobe study of metalliferous sediment components. Earth Planet. Sci. Lett. 40, 243-251.

DYmond J., Coruss J. B., Heath G. R., Feid C. W., Dasch E. J. and VEEH H. H. (1973) Origin of metalliferous sediments from the Pacific Ocean. Geol. Soc. Amer. Bull. 84, 3355-3372.

EDMOND J. M., CORLISS J. B. and GORDON L. 1. (1979a) Ridge crest hydrothermal metamorphism of the Galapagos Spreading Center and reverse weathering. In Deep Drilling Results in the Atlantic Ocean: Ocean Crust (eds. M. TALWAN et al.) Amer. Geophys. Union, Ewing Series 2, 383390.

Edmond J. M., Measures C., Mangum B., Grant B., SClATER F. K., COLLIER R., HUdSON A., GORDON L. I. and Coruss J. B. (1979b) On the formation of metal-rich deposits of ridge crests. Earth Planet. Sci. Lett. 46, 19-30.

ELDERFIELD H. and GrEaves M. J. (1981) Negative cerium anomalies in the rare earth element patterns of oceanic ferromanganese nodules. Earth Planet. Sci. Lett. 55, 163170.

EldERField H. and GREAves M. J. (1982) The rare earth elements in seawater. Nature 296, 214-219.

FlanagaN F. J. (1973) 1972 values for international geochemistry reference samples. Geochim. Cosmochim. Acto 37, 1189-1200.

GOLDBerg E. D., Kolde M., SCHMIT R. A. and SMITH, R. H. (1963) Rare earth element distributions in the marine environment. J. Geophys. Res. 68, 4209-4217.

Gordon C. E., Randle K., Goles G. D., Coruiss J. B., BEESEN M. H. and OXLEY S. S. (1968) Instrumental activation analysis of standard rocks with high resolution $\mathrm{X}$ ray detectors. Geochim. Cosmochim. Acta 32, 364-396.

HASKIN L. A., FREY F. A., SCHMTTT R. A. and SMTTH R. H. (1966) Meteoric, solar and terrestrial rare-earth distributions. In Physics and Chemistry of the Earth 7, (eds. L. H. Ahrens et al.), pp. 167-322, Pergamon Press.

HøGDAHL O. T., MELSON S. and Bowen V. (1968) Neutron activation analysis of lanthanide elements in seawater. $A d v$. Chem. Ser. 73, 308-325.

KLINKHAMMER G., ELDERFIELD H. and HUDSON A. (1983)
Rare earth elements in seawater near hydrothermal vents. Nature 305, 185-188.

KRAUSKOPF K. B. (1957) Separation of manganese from iron in sedimentary processes. Geochim. Cosmochim. Acta 12, 61-84.

LEINEN M. (1981) Metal-rich basal sediments from northeastern Pacific DSDP sites. In Initial Reports of the Deep Sea Drilling Project (eds. R. S. YeATs, B. U. HAg et al.), Vol. 63. U.S. Gov't. Printing Office, Washington, D.C

LEINEN M., REA D. K. et al. (in press) Initial Reports of the Deep Sea Drilling Project. Vol. 92, U.S. Gov't. Printing Office, Washington, D.C.

LUPTON J. E. and CRAIG H. (1981) A major Helium-3 source at $15^{\circ} \mathrm{S}$ on the East Pacific Rise. Science 214, 13-18.

LYLE M. (1981) The formation and growth of ferromanganese oxides on the Nazca Plate. Geol. Soc. Amer. Mem. 154, 269-295.

LYLE M., OWEN R. M. and LeINEN M. (in press). History of hydrothermal sedimentation at the East Pacific Rise, $19^{\circ} \mathrm{S}$. In Initial Reports of the Deep Sea Drilling Project (eds. M. LEINEN, D. K. REA et al.), Vol. 92, U.S. Gov't. Printing Office, Washington, D.C.

LYNN D. C. and BONATT E. (1965) Mobility of manganese in diagnesis of deep-sea sediments. Mar. Geol. 3, 457-474.

MoTtL M. J. and SEYFRIED W. E. (1980) Sub-seafloor hydrothermal systems: rock- vs. seawater-dominated. In Seafloor Spreading Centers: Hydrothermal Systems (eds. P. A RONA and R. P. LOWELL), pp. 66-82. Dowden, Hutchinson and Ross, Inc.

OWEN R. M. and MACKIN J. E. (1980) Authigenic associations between selected rare earth elements and trace metals in lacustrine sediments. Environm. Geol. 3, 131-137.

OWEN R. M. and RUHLIN D. E. (in press). Interlaboratory comparison of Leg 92 standard sediment sample analyses. In Initial Reports of the Deep Sea Drilling Project (eds. M. LeINEN, D. K. REA et al.), Vol. 92, U.S. Gov't. Printing Office, Washington, D.C.

PIPER D. Z. (1974a) Rare earth elements in the sedimentary cycle: a summary. Chem. Geol. 14, 285-304.

PIPER D. Z. (1974b) Rare earth elements in ferromanganese nodules and other marine phases. Geochim. Cosmochim. Acta 38, 1007-1022.

REA D. K. (in press). Southeast Pacific Ocean transect, Tahiti to Panama: geophysical profiles from D.S.D.P. Leg 92. In Initial Reports of the Deep Sea Drilling Project (eds. M. Leinen, D. K. ReA et al.), Vol. 92, U.S. Gov't. Printing Office, Washington, D.C.

RUHLIN D.E. and OWEN R. M. (in press). Factors influencing the rare earth element composition of hydrothermal sediments, East Pacific Rise. In Initial Reports of the Deep Sea Drilling Project (eds. M. LeINEN, D. K. REA et al.), Vol. 92, U.S. Gov't. Printing Office, Washington, D.C.

ThOMSON J., Carpenter M. S. N., COLley S., Wilson T. R. S., Elderfield H. and KenNedY H. (1984) Metal accumulation rates in northwest Atlantic pelagic sediments. Geochim. Cosmochim. Acta 48, 1935-1948.

TOTH J. R. (1980) Deposition of submarine crusts rich in manganese and iron. Geol. Soc. Amer. Bull. 91, 44-54. 